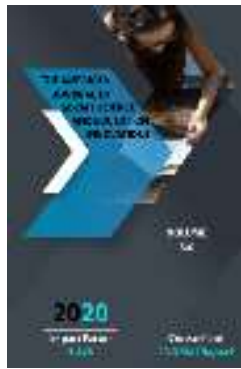

Journal Website: http://usajournalshub.c om/index,php/tajssei

Copyright: Original content from this work may be used under the terms of the creative commons attributes 4.0 licence.

\section{Lectures For Humanitarian Faculty Students And Its Effective Conduct}

\author{
Shohida Olimjonovna Boltaeva \\ Lecturer, Department Of Algebra And Geometry, Termez State University, Uzbekistan \\ Yulduz Bakhriddinovna Bakhriddinova \\ Lecturer, Department Of Algebra And Geometry, Termez State University, Uzbekistan
}

\title{
ABSTRACT
}

This article discusses the role of teachers in the organization and conduct of meaningful lectures on mathematics for students of the humanities, the state of motivation of students of the humanities, especially the motivation to study mathematics, and the effectiveness of the educational process.

\section{KEYWORDS}

Mathematics, lecture, lesson requirements, teaching, process, knowledge, skill, qualification, student, person, memory, consistency, problem-based learning.

\section{INTRODUCTION}

According to President of our country Sh.M.Mirziyoev noted, "The cornerstone of mathematics was laid by our great ancestors, such as Al- Khwārizmī, Ahmad Fergani and Abu Rayhan Beruni. It has in our blood. Nowadays, our goal in the development of this science is to create a competitive environment in mathematics, to train mature personnel in the field of industry and engineering. Indeed, large-scale reforms are being carried out in our country to develop the science of mathematics.
In particular, a target program has been developed to improve the quality of mathematical education in the Republic of Uzbekistan for 2020-2023, to increase the efficiency and practical significance of research. Increasing the volume of training in higher mathematics, In order to fully master the subject "Higher Mathematics" in the curricula adopted in the relevant bachelor's degree programs in higher education institutions, a new "Number Theory", "Mathematical Modeling", Introduction of sections "Theory of graphs", increase the 
duration of study on the subject "Higher Mathematics" from 2020-2021 academic year from 2 to 4 semesters by increasing the number of hours of some parts of the subject, a separate universal textbook in mathematics for engineering, natural sciences, humanities bachelor's degree competition for the creation and announcement of various grants, revision and simplification of mathematics programs taught in the bachelor's degree programs in the humanities, animations based on modern information technologies in mathematics, the tasks of preparation and publication of educational literature on the basis of graphic materials were put forward.

Further improvement of the system of teaching mathematics at all stages of education, support of effective work of teachers, expansion of the scope and practical significance of research work, strengthening ties with the international community, as well as in order to ensure the implementation of the tasks set out in the state program for the implementation of the Action Strategy for the five priority areas of development of the Republic of Uzbekistan in 2017-2021 in the "Year of Science, Enlightenment and Digital Economy": improving the quality of teaching mathematics, developing research and introducing scientific developments as priorities, creating and implementing an online learning platform, increasing the effectiveness of distance learning, introducing mechanisms to ensure the transparency of the assessment system, introduction of a national certification system for assessing the level of knowledge of mathematics, increasing the number of classes in mathematics in the relevant areas and specialties of higher education and improving the quality of education, ensuring an inextricable link between research in the field of mathematics with production, the development of applied mathematics and the development of mathematical solutions based on modeling problems in economics, support of talented youth studying and conducting research in the field of mathematics, the development of relations with higher education institutions and scientific organizations abroad, the gradual transformation of scientific and educational institutions of our country to the level of the world's leading scientific centers in mathematics.

\section{THE MAIN FINDINGS AND RESULTS}

When teaching mathematics to students of humanitarian faculties of higher educational institutions, the following requirements are imposed:

a) Purposefully, the formation of students' logical thinking skills by explaining the content of the topic set for the purpose of the lesson;

b) Rational distribution of the lesson and its content - the formation of knowledge, skills and thinking activities in relation to mathematical, intellectual and educational activities through the correct distribution of the lesson and its types, as well as students'mastery of the content of the subject in mathematics;

c) Selection of teaching methods and tools to determine which of the methods of explanation, research and inference, depending on the content of the topic, students better master the content of the topic, to achieve the effectiveness of the lesson;

d) To organize the learning process in different ways to form students' cognitive activities during the lesson.

The lesson is the basis of the educational process, and each lesson reveals the content, the relationship between the purpose, content, form, methods and means of the 
educational process. Mathematics classes are conducted in the following types: introduction to the content of a new topic, strengthening a new topic, testing students' knowledge, skills and abilities, review and generalization of teaching materials.

A lecture is a logically coherent, coherent and understandable presentation of a certain scientific issue, built on a dialecticalmaterialistic basis, often accompanied by experiments and visual aids. The main task of the lectures is to introduce students to science, which is the first acquaintance with the basic scientific and theoretical rules and methodology of the field. The material offered to students in the lecture should help them to form an idea of this field of knowledge, to understand its basic ideas and determine its relationship with other areas of scientific knowledge, as well as to identify ways and means of applying this knowledge in practice.

A set of lecture topics based on scientific knowledge determines the direction, content and nature of all types of educational activities, as well as the independent work of students.

One of the distinguishing features of higher education is the combination of scientific and educational foundations in lectures. This is one of the most important tasks of any higher education institution, because science enriches the educational process and at the same time determines its content. When making the initial selection of material for each lecture, it is necessary to take into account the readiness of the teacher for an auditory perception of the material at a certain level of abstraction, generalization and science. The material delivered to the students should be important, the most vivid and convincing. The factual material in the lecture should not be relatively large, that is, it should be as much as necessary for students to understand the issue. The content and nature of the material presented in the lectures differ in their structure, depending on the teaching methods. However, there are general methodological rules that must be followed when reading reports. This is, first of all, to provide information about the plan of the lecture, which must be followed by the educator. Second, before the lecture, the audience should be reminded of the issues discussed earlier. Previously learned material should be associated with new material. It is necessary to indicate the role, place and importance of new material in this science, in the system of other sciences. Third, it is necessary to draw conclusions on each of the rules analyzed in the course of each report and repeat it. Finally, at the end of each lecture, students should clarify and conclude what they learned in that lecture.

Lecture has always been the main subject of the educational process in high school. At the lecture, students receive clear information, a set of knowledge that they need to understand and master. In addition, the lecture should teach students to think critically, analyze the material studied, make independent generalizations and conclusions, and justify them. To maintain constant communication with the audience, the presenter must not only perfectly know his material, but also know his audience, its background, interests and working methods. In particular, the difficulties inherent in the first-year students of any faculty are shaped by the school and are related to the stereotypes of cognitive activity we have discussed above. For example, the lack of logical operations to understand the material being studied leads students to try to understand the material, to get to its essence, 
and to remember it rather than to draw conclusions. This situation has a negative impact on students' perception of scientific information, which is carried out during the lecture. In this lecture, the student is required to listen simultaneously, to develop an idea of the material being studied, and to separate and write down the main issues. However, according to K. Simashko, only $36 \%$ of students understand the content of the lectures, $15 \%$ do not distinguish the main thing, $27 \%$ do not have time to write, and only $22 \%$ of students do not feel any difficulty. This is often due to the fact that: the speaker does not pay enough attention to the information he gives, or the listening skills are not sufficiently developed; high speed of mental activity, which prevents the perception of new information; dislike for the opinions of others; the need to bite off (a person often tries to interpret what is said). In order to overcome these negative factors, it is necessary to form in students the ability to self-manage their attention. These are manifested in the ability to distinguish basic rules, in the ability to conduct a step-by-step analysis, in the ability to go before the speaker, that is, in finding the next rules of the speech, in the readiness to always listen to the end. In addition, it is necessary to teach how to take a synopsis side by side with the description of the material. One such teaching method might be this: the speaker turns his or her words into a synopsis and at the same time introduces the students to how they are doing it. Therefore, the most important task of a speaker working with firstyear students of any faculty is to effectively organize the student's work during the lecture, which includes listening, understanding and comprehending the material and converting the information into a short note to help quickly recreate the main content of the lecture. lies in the active process.
Thus, a lecture can be achieved by understanding students, well-coordinated work, first of all, the content of lectures, the accuracy of their structure, the use of attention-grabbing techniques, compliance with all general requirements for the preparation and conduct of a lecture. However, the effectiveness of lecture sessions depends not only on their scientific content, but also on the subsequent work of students on a deeper understanding and mastery of the studied material. Listening to a lecture in the classroom consists of a primary perception and understanding of the learning material, which is usually superficial, incomplete, and sometimes less clear. Further independent work of students on the material of the lecture is also required by the laws of its mastering.

In the development of lectures it is necessary to pay attention to the state of motivation of students of humanities faculties, in particular, the motivation to study mathematics. Students with creative motivation to study do not have special problems in the study of mathematics. The consequences of a negative attitude are: distraction (division) in training, inability to recover from work after distraction, difficulty, and impairment of activity after errors. There is a predominance of motives for avoiding inconveniences, a lack of interest in the content and process of reading. In addition, problems in the study of mathematics also arise due to the lack of formation of learning activities. A passive attitude to reading is characterized by avoidance of difficulties, lack of independent goals, failure to return to unresolved issues, negative boredom, feelings of insecurity, and emotional instability. Motives of interest in external learning outcomes are not constant. However, these students can do some 
learning activities according to the instruction and pattern, which is their positive trait.

The results of students' work at lectures depend on the manifestation of the properties of attention, in particular, its concentration in one place. For most humanities students, it is low due to a lack of positive motivation. For the educator to be effective, we recommend splitting a lecture material into two blocks. The first block of lectures is held for the whole group of students and is aimed at forming a positive motivation to learn mathematics.

The main tasks of the teacher in organizing the teaching process in the first block of lectures are as follows:

i. Formation of interest (emotional, intellectual interest);

ii. Activation of students' thinking activities;

iii. The organization of students' work on lectures.

\section{CONCLUSION}

The solution of the first task is made on the basis of the study material, which is presented to the students and is accompanied by known and unknown facts. For example, the stages of development of mathematics as a science, in the description of which there is a repetition of mathematical concepts (types of numbers, variables, derivatives, integrals) learned in school. When discussing the general recommendations of the departments of mathematics, the knowledge in mathematics obtained at school is systematized, and the material on geometry, topology algebraic structures set theory by N.I. Lobachevsky is completely new. The activation of students' thinking can be carried out with the help of problematic elements of teaching special attention should be paid to the formation of a synopsis of a lecture when students perform a practical task, for example, gluing a Mobius strip or proving the implementation of the axiom of parallelism by N.I. Lobachevsky using the Felik Klein model. This is due to the stereotypes of education that have developed in the school. This form of work is most effective: the main provisions of the lecture are written under the guidance of a teacher, and the rest of the material is listened to. In developing reports that contain a large amount of mathematical material, are included in the second block, and are recommended for group work, the main focus should be on making sure that the proposed material is accessible to students. A distinctive feature of mathematics for humanities students is that it is usually listened to by people far removed from mathematics. They cannot be fascinated by the beauty of logical structures. In order to stimulate their cognitive activity, to activate their attention, the described material should be connected with the specialization of students. This is primarily related to the selection of examples that demonstrate this or that mathematical concept. When describing the material of the lecture, it is necessary to use a variety of exhibitions, mainly operational, structural exhibitions and sequential exhibitions, taking into account the characteristics of the cognitive activity of students of humanities faculties.

When a student listens to a lecture, the information received is mainly recorded in the operative memory and is quickly forgotten. Strong skill is associated with long-term memory. When describing the lecture material, it is necessary to use a variety of exhibitions, mainly operational, structural and regular exhibitions, taking into account the peculiarities of the cognitive activity of students of humanitarian faculties. Due to the disorganized memory of students of 
humanitarian faculties, after the explanation, it is necessary to repeat the main provisions of the lecture. Problem-based learning elements such as problem solving and content can be used to energize students in a lecture.

\section{REFERENCES}

1. Mirziyoev Sh.M. Together we will build a free and prosperous, democratic state of Uzbekistan. Tashkent: “Uzbekistan". 2016.

2. Mirziyoev Sh.M. "On measures to improve the quality of education and research in the field of mathematics." Tashkent: May 7, 2020. PD-4708

3. Leontiev A.N. Selected psychological works: In 2 volumes. Moscow: 1983.
4. Alikhanov S. "Methods of teaching mathematics" Revised II edition. Tashkent: 1997

5. Alikhanov S. "Methods of teaching mathematics". Tashkent: 2011

6. Ishmuhamedov R. J. "Ways to increase the effectiveness of education through innovative technologies". Tashkent: 2016.

7. Davidov V.V. "Development and educational psychology". Moscow: Pedagogy. 1992.

8. Stolyar A.A. "Pedagogy of Mathematics". Minsk: 1988.

9. Stolyar A.A. "Methods of teaching mathematics". Minsk: 1993.

10. Stolyar A.A. "The role of mathematics in the humanization of education" Mathematics in school. 1990. 